\title{
FALLS AND OUTCOMES AMONGST OLD PEOPLE IN RURAL DWELLINGS
}

\author{
A.O. Adebiyi ${ }^{1}$, O.C. Uchendu ${ }^{1}$, O.T. Ikotun ${ }^{1}$, O.W. Oluleye ${ }^{1}$, O.P. Olukotun ${ }^{1}$ \\ ${ }^{1}$ Department of Community Medicine, College of Medicine, University of Ibadan.
}

Correspondence:

Dr A.O. Adebiyi

Department of Community Medicine

College of Medicine,

University of Ibadan

E-mail: adebiyi20012002@yahoo.com

\begin{abstract}
Background: Falls are the leading cause of injury deaths among people 65 years and older. This study gives an insight into the prevalence of falls among older people and how they occur in a rural setting in Nigeria.

Methods: A community based survey of 210 consenting old people aged 65 years and above selected using a multi-stage sampling technique was done. Study instrument was a semi-structured interviewer administered questionnaire and visual acuity was tested using Snellens chart.

Results: Incidence of falls was $21.4 \%$. Of those who had falls, $86.7 \%$ were walking while $11.1 \%$ were either sitting or running when it occurred. The nature of the fall was tripping in $44.4 \%$, slipping in $35.6 \%$ and hitting an object in $17.8 \%$ of cases. Consequences of falls included pain $48.9 \%$, bruises $22.2 \%$, lacerations $13.3 \%$ and fractures $11.1 \%$. Females had more falls than males; $23.8 \%$ vs $19.0 \%, \mathrm{p}=0.40$. Major injuries resulting from falls also occurred more frequently amongst females than males; $30.7 \%$ vs. $15.0 \%, p=0.3$. History of diabetes and alcohol use increased the odds of falling (OR 4.1, 95\% CI 1.0 - 16.0; OR 2.2, $95 \%$ CI $1.0-4.6$ respectively). Being in a monogamous marriage and having normal sight were protective of having falls (OR 0.4, 95\% CI 0.2-0.9; OR 0.4, 95\% CI $0.2-0.9$ respectively).

Conclusion: Falls often occur from tripping and slipping while females are more likely to have major injuries. Risk factors for falls were alcohol use and diabetes while having normal sight and being monogamous were protective. Prevention should aim at a life course approach to addressing these intrinsic and extrinsic factors.
\end{abstract}

\section{INTRODUCTION}

A fall is a sudden, unintentional change in position causing an individual to land at a lower level, on an object, the floor, or the ground, other than as a consequence of sudden onset of paralysis, epileptic seizure or overwhelming external force ${ }^{1}$. Internationally, it is estimated that one in three people over 65 years living in the community will fall each year ${ }^{2,3}$ and in half of these cases, falls are recurrent ${ }^{3}$. About $20-30 \%$ of those who fall suffer injuries that reduce mobility and independence and increase the risk of premature death $^{4,5}$. In addition, falls are the leading cause of injury deaths among people 65years and older and half of these falls occur in their own home $e^{6,7}$. Thus falls and fall-related injuries among older people are now becoming major issues for health and care givers world wide?

The risk factors for falls have been described as internal and external or in more exact terms as intrinsic/ personal such as impaired strength, poor vision e.t.c and extrinsic/environmental like loose surfaces and

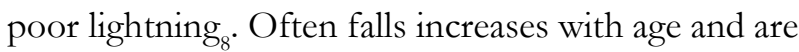
more commoner amongst females than males ${ }^{9,10}$. Other factors that have been documented to increase the risk of falling include: a previous history of fall, living alone, chronic disease burden, dizziness and use of one or more medications. Furthermore, some studies have reported that between $30 \%$ and $50 \%$ of falls among older people living in communities are due to environmental causes while $20 \%$ of falls are due to major external factors that can cause any healthy adult to fall ${ }^{11,12}$. Thus environmental hazards like poor lighting, slippery floors, and uneven surfaces would contribute substantially to the rising prevalence of falls.

The consequences of falls is the increased morbidity and mortality often associated with them ${ }^{4,5}$. Injuries amongst the elderly reduce length and quality of life 
and take up a large proportion of the health spending especially in a rural setting, but its prevention is quite cheap and simple. This study documents the occurrence of falls and its associated risk factors among older people in a rural setting in Nigeria. This information which is largely unavailable in Nigerian studies would be crucial in prevention of falls amongst the elderly.

\section{METHODS}

A community based survey of 210 consenting old people aged 65 years and above residing in Oyo State, Nigeria was done using an interviewer administered questionnaire. Igboora is the headquarters of Ibarapa Central Local Government in Oyo State, southwestern Nigeria. It is a rural town slowly undergoing urbanization with a population of . The minimum sample size calculated at $5 \%$ precision using a prevalence of falls of $14 \%$ (13) among community elderly people was 184 and the sampling technique was multistage. Two blocks were selected out of the six blocks in Igboora by simple random sampling and all consenting households within the selected wards were enrolled for the study. One male and one female were selected as the final sampling unit from each consenting household. Where there was more than one female or male in the household, balloting was done to select the study participant. Informed consent was obtained from each participant before the interview. Questionnaire contained questions on sociodemographic characteristics, existing morbidities and related issues, occurrence of falls, outcomes of falls and social habits. Visual acuity was also checked using the Snellens chart. Research assistants were medical students who had earlier been trained on the use of the Snellens chart. However, a training test run was done to standardize its use by all research assistants. Low vision was defined as vision of $6 / 18$ and below. At the end of each interview, health education was given and any interviewee with acute or chronic condition for which medical attention has not been sought was referred to the health centre within the community. Data was analysed using the SPSS version 11.0

\section{RESULTS}

About $40 \%$ of respondents were within the age group 65-69 years while those in the age group e" 85 years were the least. Males and females were of equal proportion. Majority $159(74.3 \%)$ were married while $48(22.9 \%)$ were widows. Majority 131 (62.4\%) were also from a polygamous set-up. The predominant occupation of respondents was trading $99(47.1 \%)$ followed by farming $67(31.9 \%)$.

Altogether, $21.4 \%$ of respondents have experienced at least one fall within 1 year preceding the study.
Regarding the most recent fall, 39 (86.7\%) were walking, $4(8.9 \%)$ sitting and $1(2.2 \%)$ running when the fall occurred; 1 person $(2.2 \%)$ couldn't say what he was doing before the fall. The nature of the fall was tripping in $20(44.4 \%)$, slipping in $16(35.6 \%)$ and hitting an object in $8(17.8 \%)$ of cases; 1 person $(2.2 \%)$ couldn't say what happened. Following the fall, 10 $(22.2 \%)$ sustained bruises, $22(48.9 \%)$ pain only, 6 $(13.3 \%)$ lacerations, $5(11.1 \%)$ fractures and amongst $2(4.4 \%)$, nothing significant. All those who had fractures were females.

\begin{tabular}{|l|r|r|}
\hline Characteristic $\quad \mathrm{N}=210$ & $\mathrm{n}$ & $\%$ \\
\hline Age & & \\
$65-69$ & 90 & 42.9 \\
$70-74$ & 58 & 27.6 \\
$75-79$ & 27 & 12.9 \\
$80-84$ & 18 & 8.6 \\
$=85$ & 17 & 8.1 \\
Sex & & \\
Male & 105 & 50.0 \\
Female & 105 & 50.0 \\
Marital status & & \\
Married & 159 & 74.3 \\
Cohabiting & 3 & 1.4 \\
Divorced & 3 & 1.4 \\
Widowed & 48 & 22.9 \\
Marital setting & & \\
Monogamous & 79 & 37.6 \\
Polygamous & 131 & 62.4 \\
Occupation & & \\
Housewife & 4 & 1.9 \\
Farmer & 67 & 31.9 \\
Trader & 99 & 47.1 \\
Artisan & 26 & 12.4 \\
Professional & 14 & 6.7 \\
\hline
\end{tabular}

Table 1: Socio-demographic characteristics of elderly respondents in Igbo-Ora

\begin{tabular}{|l|r|r|}
\hline Characteristic N = 210 & $\mathrm{n}$ & $\%$ \\
\hline Activity when fall occurred & & \\
Walking & 39 & 86.7 \\
Sitting & 4 & 8.9 \\
Running & 1 & 2.2 \\
Can't say & 1 & 2.2 \\
Nature of fall & & 8.1 \\
Tripping & 20 & 44.4 \\
Slipping & 16 & 35.6 \\
Hitting an object & 8 & 17.8 \\
Can't say & 1 & 2.2 \\
Outcome of fall & & \\
Swelling and pain & 22 & 48.9 \\
Bruises & 10 & 22.2 \\
Lacerations & 6 & 13.3 \\
Fractures & 5 & 11.1 \\
Nothing significant & 2 & 4.4 \\
\hline
\end{tabular}

Table 2. Characteristics of fall 
A greater percentage of those $\geq 75$ years $(25.8 \%)$ experienced falls compared to those aged 70-74years $(24.1 \%)$ and $65-69$ years $(16.7 \%) ; \mathrm{p}=0.33$. those within monogamous marriages were less likely to have experienced a fall compared to those in a polygamous marriages, $13.9 \%$ vs $26.0 \%$; $\mathrm{p}=0.04$. More females $(23.8 \%)$ experienced falls than the males $(19.0 \%) ; \mathrm{p}=$ 0.40 . Females had more major injuries compared to males, $30.7 \%$ vs. $15.0 \%, \mathrm{p}=0.3$. Also, more of those who use alcohol $(34.4 \%)$ had falls compared with the non-users $(15.8 \%) ; \mathrm{p}=0.002$.
Logistic regression analysis revealed that being in a monogamous marriage was protective of having falls; OR $0.4,95 \%$ CI $0.2-0.9$. The odds of having falls was higher among diabetic than non-diabetic respondents; OR 4.1, 95\% CI 1.0 - 16.0. In addition, the use of alcohol increased the odds of having falls; OR 2.2, 95\% CI 1.0 - 4.6 and having a normal sight was protective of having falls; OR $0.4,95 \%$ CI $0.2-$ 0.9 .

\begin{tabular}{|c|c|c|c|}
\hline \multirow[t]{2}{*}{ Characteristic } & \multicolumn{3}{|c|}{ History of Fall } \\
\hline & Yes n $(\%)$ & Non $(\%)$ & \\
\hline \multicolumn{4}{|l|}{$\overline{A g e}$} \\
\hline $65-69$ & $15(16.7)$ & $75(83.7)$ & \\
\hline $70-74$ & $14(24.1)$ & $44(75.9)$ & \\
\hline$\geq 75$ & $16(25.8)$ & $46(74.2)$ & $\mathrm{p}=0.33$ \\
\hline \multicolumn{4}{|l|}{ Sex } \\
\hline Male & $20(19.0)$ & $85(81.0)$ & \\
\hline Female & $25(23.8)$ & $80(76.2)$ & $\mathrm{p}=0.40$ \\
\hline \multicolumn{4}{|l|}{ Marital setting } \\
\hline Monogamous & $11(13.9)$ & $68(86.1)$ & \multirow[b]{2}{*}{$\mathrm{p}=0.04$} \\
\hline Polygamous & $34(26.0)$ & $97(74.0)$ & \\
\hline \multicolumn{4}{|l|}{ Well lit room during fall } \\
\hline Yes & $36(21.4)$ & 132 (78.6) & \multirow[b]{2}{*}{$\mathrm{p}=1.00$} \\
\hline No & $9(21.4)$ & $33(78.6)$ & \\
\hline \multicolumn{4}{|l|}{ Alcohol use } \\
\hline Yes & $22(34.4)$ & $42(65.6)$ & \multirow{4}{*}{$\mathrm{p}=0.002$} \\
\hline \multirow[t]{2}{*}{ No } & $23(15.8)$ & $123(84.2)$ & \\
\hline & \multicolumn{2}{|c|}{ Severity of injury } & \\
\hline \multirow{2}{*}{$\begin{array}{l}\text { Male } \\
\text { Female }\end{array}$} & $\mathrm{Ma}$ & Minor & \\
\hline & $\begin{array}{l}17(85.0) \\
18(69.3)\end{array}$ & $\begin{array}{l}3(15.0) \\
8(30.7)\end{array}$ & $*_{p}=0.30$ \\
\hline
\end{tabular}

Table 3: Factors associated with falls

The association between pre-existing morbidities and falls are shown in table 4. More diabetic (54.5\%) had falls compared to the non-diabetic (19.6\%); $\mathrm{p}=0.06$. More hypertensive $(25.9 \%)$ had falls than the nonhypertensive $(19.9 \%) ; \mathrm{p}=0.35$. A greater percentage of those who had experienced stroke previously $(50.0 \%)$ had falls compared to those who had not $(20.6 \%) ; p=0.08$. A greater proportion of those with chronic joint pain $(28.9 \%)$ had falls compared to those without $(15.0 \%) ; \mathrm{p}=0.02$. A greater percentage of those with re-current history of dizziness $(38.1 \%)$ had falls than those without such history $(19.6 \%) ; \mathrm{p}=0.05$. A lesser proportion of full sighted respondents $(17.4 \%)$ experienced falls as compared to the partial sighted/blinded (30.3\%); $\mathrm{p}=0.03$.

\section{DISCUSSION}

This study documented the incidence of falls amongst the respondents in Igboora to be $21.4 \%$. This was lower than the $58.3 \%$ reported by Wojszel and Bien in their study among older people living in the community and this may be due to the fact that they studied a relatively older community aged 75 years and over ${ }^{14}$. In addition, the African rural communities are quite conducive to functionality of the older person. Our study highlighted that older persons were more likely to have experienced falls than the relatively younger people i.e., $16.7 \%$ amongst those in the age group 65 69 compared to $25.8 \%$ amongst those 75 years and above. Tripping and slipping have been documented as extrinsic factors for falling especially in areas where 


\begin{tabular}{|c|c|c|c|}
\hline Disease & $\begin{array}{c}\text { Had fall } \\
\mathrm{n}(\%)\end{array}$ & $\begin{array}{l}\text { No fall } \\
\mathrm{n}(\%)\end{array}$ & $\mathbf{P}$ value \\
\hline Diabetes & & & \\
\hline Yes & $6(54.5)$ & $5(45.5)$ & \\
\hline No & $39(19.0)$ & $160(80.4)$ & $p=0.06$ \\
\hline Hypertension & & & \\
\hline Yes & $4(25.9)$ & $40(74.1)$ & \\
\hline No & $31(19.9)$ & $125(80.1)$ & $\mathrm{p}=0.35$ \\
\hline History of stroke & & & \\
\hline Yes & $3(50.0)$ & $3(50.0) 80$ & \\
\hline No & 42 (20.6) & $162(79.4)$ & $\mathrm{p}=0.11$ \\
\hline Chronic joint pain & & & \\
\hline Yes & $28(28.9)$ & 69 (71.1) & \\
\hline No & $17(15.0)$ & $96(85.0)$ & $\mathrm{p}=0.02$ \\
\hline History of tremor at rest & & & \\
\hline Yes & $3(60.0)$ & $2(40.0)$ & \\
\hline No & $42(20.5)$ & $163(79.5)$ & $p=0.07$ \\
\hline History of dizziness & & & \\
\hline Yes & $8(38.1)$ & $13(61.9)$ & \\
\hline No & 37 (19.6) & $152(80.4)$ & $\mathrm{p}=0.05$ \\
\hline Visual acuity & & & \\
\hline Full sighted & 25 (17.4) & $119(82.6)$ & \\
\hline Partial sighted/blind & $20(30.3)$ & $46(69.7)$ & $\mathrm{p}=0.03$ \\
\hline
\end{tabular}

Table 4: Morbidities and falls

objects are placed haphazardly, rugs that move across the floor easily are used and crooked or slippery floor and carpet skirting boards that protrude are common occurrences ${ }^{15}$. Our study supports this assertion by showing that tripping and slipping were responsible for $45.5 \%$ and $36.4 \%$ of falls respectively. However, the assertion that lighting is a strong extrinsic factor for falling was not supported by our study. This may be due to the fact that the typical structure of the rural dwelling place admits light quite easily. So only a small number of people (forty-two) reported their rooms as not being well lit when falls occurred.

Falls were reported more by those who were polygamous marriages probably because of the relatively less space availability per person within a polygamous setting with a high probability of being cluttered. The higher proportion of females having falls is not unusual as other studies have documented similar findings ${ }^{16}$. Females do a lot of household chores and this explains their susceptibility to falls. However, it has also been documented that this dissimilarity of gender related falls is a function of age as the older women fall more often than men ${ }^{9,10}$. Dizziness has been reported to be common in fallers as is diabetes ${ }^{15,17}$ and this is similar to our own finding that those with history of recurrent dizziness as well as those with history of diabetes had a higher proportion of fallers. Tremor at rest indicating disease conditions like
Parkinsonism, chronic joint pain indicating conditions like arthritis and alcohol use were significantly associated with falls. Other studies have shown that the prevalence of falling actually rises with chronic disease burden ${ }^{18}$ and this is demonstrable with arthritis and alcohol use $^{19,20}$. This is related to the problem of balance and righting imperfection in the elderly. Being partially sighted or blinded was associated with a significantly increased risk of falling. Visual impairments have long been identified as a common health problem among the elderly and studies have demonstrated its association with an increased risk of falling in old age ${ }^{14}$.

The predominantly injury sustained were swelling with pain followed by bruises, lacerations and fractures. The direct consequence of this is that these injuries reduce mobility and independence and increase the risk of premature death ${ }^{4,5}$. Though the reported outcome of these falls were not substantially major, the risk of poor outcomes especially when older people are left unattended to can be quite substantial. Falls may also result in a psychological trauma known as fear of falling ${ }^{21,22}$. Major injuries also occurred more amongst the females than the males with all the fractures occurring amongst the females. Postmenopausal, women have been known to be at increased risk of having fractures resulting from hormone related osteoporosis. 


\begin{tabular}{|c|c|c|c|}
\hline Variable & Odds Ratio & $95 \% \mathrm{CI}$ & $\mathrm{p}$ value \\
\hline \multicolumn{4}{|l|}{ Family setting } \\
\hline Polygamous & 1 & & \\
\hline Monogamous & 0.4 & $0.2-0.9$ & 0.02 \\
\hline Diabetes & & & \\
\hline No & 1 & & \\
\hline Yes & 4.1 & $1.0-16.0$ & 0.04 \\
\hline Chronic joint pain & & & \\
\hline No & 1 & & \\
\hline Yes & 2.0 & $0.9-4.2$ & 0.07 \\
\hline History of tremor & & & \\
\hline No & 1 & & \\
\hline Yes & 3.4 & $0.4-32$ & 0.29 \\
\hline Recurrent history of dizziness & & & \\
\hline No & 1 & & \\
\hline Yes & 1.6 & $0.5-4.6$ & 0.42 \\
\hline Alcohol use & & & \\
\hline No & 1 & & \\
\hline Yes & 2.2 & $1.0-4.6$ & 0.04 \\
\hline Visual acuity & & & \\
\hline Partial sighted/blinded & 1 & & \\
\hline Full sighted & 0.4 & $0.2-0.9$ & 0.03 \\
\hline
\end{tabular}

Table 5: Predic tors of fall

Overall, our study documented the predictors of falling in old age as diabetes which is associated with a 4 fold increased odds and alcohol use with a 2 fold increased odds. Suffice it to say that alcohol is present in many herbal preparations at the rural level. Being full sighted and coming from a monogamous setting was also significantly protective of experiencing falls amongst the elderly. These results further reinforce the fact that predictors of falls amongst old people are often multifactorial. However, a recent meta-analysis showed that evidence of benefit from multifactorial risk assessment and targeted intervention for falls in primary care, community, or emergency care settings was limited and reductions in the number of fallers may be smaller than thought ${ }^{24}$.

We have documented that falls occur quite commonly amongst older people living within rural settings. Conversely, the public health measures for its prevention are quite cheap and simple. Based on this, we recommend a life course approach (a concept of life as a journey with different phases and transitions and an examination of experiences common to these transitions ${ }^{25}$ ) as a way of addressing the contributing intrinsic and extrinsic factors identified in this study.

\section{REFERENCES}

1. Tinetti, M.E., Baker, D.I., Dutcher, J., Vincent, J. E., \& Rozett, R.T., Reducing the risk of falls among older adults in the community, Berkeley, CA, Peaceable Kingdom Press, 1997

2. Tinetti, M.E., Speechey, M. \& Ginter, S.F. Risk factors for falls among elderly persons living in the community. New England Journal of Medicine, 1988; 319:1701-1707.

3. Nevitt, M.C., Cummings, S.R., Kidd, S. \& Black, D. Risk factors for recurrent nonsyncopial falls: a prospective study. Journal of American Medical Association. 1989; 261:2663-2668.

4. Tinetti M.E., Speechley M. Prevention of falls among the elderly. New England Journal of Medicine. 1989; 320:1055-1059.

5. Freeman C. et al. Quality improvement for people with hip fracture: experience from a multi-site audit. Quality and safety in health care. 2002;11:239-245.

6. Lord S.R., McLean D., Strathers G. Physiological factors associated with injurious falls in older people living in the community. Gerontology. 1992; 38:338-346.

7. Tinetti M.E. Clinical practice. Preventing falls in elderly persons. New England journal of medicine, 2003; 348:42-49. 
8. Department of Health 2004, The Falls Policy for Older Western Australians, Department of Health, Perth.

9. Campbell A.J., Spears G.F., Borrie M.J. Examination by logistic regression modeling of the variables which increase the relative risk of elderly women falling compared to elderly men. Journal of clinical epidemiology, 1990; 43:14151420 .

10. Robbins A.S. et al. Predictors of falls among elderly people. Results of two population-based studies. Archives of internal medicine, 1989; 149:1628-1633.

11. Feder G. et al. Guidelines for the prevention of falls in older people. BMJ, 2000; 321:1007-1011.

12. Lord S.R., Sherrington C., Menz H.B. Falls in older people: risk factors and strategies for prevention. Cambridge University Press, 2000.

13. Mendez R.J., Zunzunnegui M.V., Beland F. The prevalence of and factors associated with falls in older persons living in the community. Medicina Clinica 1997; 108(4):128-132.

14. Wojszel Z.B., Bieñ B. Falls amongst older people living in the community. Annales Academiae Medicae Bialostocensis. 2004 (49).

15. Todd C., Skelton D. (2004). What are the main risk factors for falls among older people and what are the most effective interventions to prevent these falls? Copenhagen, WHO Regional Office for Europe (Health Evidence Network report; http:/ /www.euro.who.int/document/E82552.pdf, accessed 15/06/2007.

16. Biderman A., Cwikel J., Fried A.V., Galinsky D. Depression and falls among c o $\mathrm{m} \mathrm{m} \mathrm{u} \mathrm{n} \mathrm{i} \mathrm{t} \mathrm{y}$ dwelling elderly people: a search for common risk factors. J Epidemiol Community Health, 2002; 56 (8): 631-636.
17. Luukinen H. et al. Predictors for recurrent falls among the home-dwelling elderly. Scandinavian journal of primary health care, 1995; 13:294-299.

18. Tinetti M. et al. Risk factors for serious injury during falls by older persons in the community. Journal of the American Geriatrics Society, 1996; 43:1214-1221.

19. Salkeld G. et al. Quality of life related to fear of falling and hip fracture in older women: a time trade off study. BMJ, 2000; 320:341-346.

20. Department of Health 2004, The Falls Policy for Older Western Australians, Department of Health, Perth. www.health.wa.gov.au/publications. Accessed 15/06/08

21. Hindmarsh J.J., Estes E.H. Jr. Falls in older persons. Causes and interventions. Arch Intem Med. 1989;149:2217-2222.

22. Tinetti M.E., Speechley M. Prevention of Fear of Falling falls among the elderly. N Engl J Med. 1989; 320:1055-1059.

23. Arken C.L., Lach H.W., Birge S.J., and Miller J.P. The Prevalence and Correlates of Fear of Falling in Elderly Persons Living in the Community. Amj Pub health 1994; 84:565-570

24. Gates S., Fisher J.D., Cooke M.W., Carter Y.H. and Lamb S.E. Multifactorial assessment and targeted intervention for preventing falls and injuries among older people in community and emergency care settings: systematic review and meta-analysis. BMJ 2008; 336; 130-133; Accessed from bmj.com on 18/01/08.

25. Stewart D., Law M., Rosenbaum P., and Williams D. A qualitative study of the transition to adulthood for youth with disabilities. Physical and occupational Therapy in Paediatrics 2001; 21: 3-22 